\title{
Numerical analyses of embankment dams containing plastic concrete cut-off walls using finite difference method (A case study: The Karkheh Embankment Dam)
}

\author{
Yadolah Pashang Pisheh ${ }^{1, *}$ and Seyd Majdeddin Mir Mohammad Hosseini 2 \\ Department of Civil and Environmental Engineering, Amirkabir University of Technology (Tehran Polytechnic), Tehran, \\ Iran.
}

Global Journal of Engineering and Technology Advances, 2021, 09(03), 143-153

Publication history: Received on 24 November 2021; revised on 29 December 2021; accepted on 31 December 2021

Article DOI: https://doi.org/10.30574/gjeta.2021.9.3.0176

\begin{abstract}
In this paper, numerical analyses have been performed on the Karkheh embankment dam with a clayey core and plastic concrete cut-off wall during construction, impounding, and permanent seepage stages. The dam has 127 meters height and is located in a high seismic hazard zone in Iran. Different stages of construction, water impounding, and steady state seepage were modelled and analyzed using the hyperbolic and Mohr-Coulomb models with the two dimensional finite difference method (FDM). So, nonlinear analyses were performed using FLAC 2D to investigate the settlements and the pore water pressure changes in different zones of the dam during above-mentioned stages and the results were compared to those of the other studies. The results show that at the end of the construction stage, the maximum settlement equal to $1.45 \mathrm{~m}$ occurs inside the clay core at the height of $65 \mathrm{~m}$. Then, after impounding of the reservoir and steady state stage, the maximum magnitude of the horizontal deformations occurs in the downstream of the dam equal to $0.55 \mathrm{~m}$; however, these magnitudes reach to $0.17 \mathrm{~m}$ at the crest of the dam. Moreover, it was shown that the maximum horizontal displacement of the plastic concrete cut-off wall has happened at the top of the wall in the clay core which is in a good agreement with the other studies' result.
\end{abstract}

Keywords: Embankment Dam; Finite Difference Method; Plastic Concrete; Cut-off Wall

\section{Introduction}

Embankment dams provide a life-sustaining resource to people in all regions of the world. They can serve several functions at once, including water supply for domestic, agricultural, industrial, community, and livestock uses. Among various types of embankment dams' failure, cracking and collapse in the clay cores and cut-off walls as the barriers preventing seepage through the dam is highly catastrophic. Therefore, providing a method to decrease the seepage of a large embankment dam is of great importance [1]. Selecting the best method to this aim depends on the materials of the foundation, the risk involved in excessive seepage from the foundation, as well as the available construction technology. Employing cut-off walls of plastic concrete material is one of the most important and effective methods used for seepage control and remediation in weak foundations of embankment dams. Plastic concrete as a proper material meets essential requirements for dams' cut-off wall construction including strength, stiffness, and impermeability. These features are crucial for the prevention of the earthquake geo-hazard's disasters in geotechnical structures [2, 3] especially, those located in seismic zones [4]. Such a material comprises a mixture of cement, aggregate (sand and gravel), water, and Na-bentonite in special proportions which has very low hydraulic conductivity and excellent ductility after reaching failure [5]. The constituents of plastic concrete materials are, in general, those of ordinary concrete materials; however, some differences exist. In plastic concrete, the aggregates' size is usually limited to a certain value and some amounts of bentonite are also added to the mixture of the concrete. This leads to a material with

\footnotetext{
${ }^{*}$ Corresponding author: Yadolah Pashang Pisheh

Dept. of Civil and Environmental Eng., Amirkabir University of Technology, No. 350, Hafez Ave., Valiasr Square, Tehran, Iran, P.0. Box: 1591634311.
} 
comparatively lower stiffness and strength [6]. The International Commission on Large Dams (ICOLD) has presented characteristics of plastic concrete and other filling materials for watertight cut-off walls [7]. According to the ICOLD recommendations, for a given plastic concrete cut-off wall, the stiffness of the plastic concrete should be limited up to maximum four to five times of the foundation material stiffness. Otherwise, excessive load concentrated on the cut-off wall may cause its cracking and failure. From the loading distribution and structural point of view, plastic concrete cutoff walls are preferred for the large dams with the foundations comprised of alluvium materials.

Field monitoring, centrifuge modeling, and numerical analysis methods were usually used to study the behavior of embankment dams containing cut-off walls. For example, the interaction mechanism between the cut-off wall and surrounding soils in the upstream cofferdam of the Three Gorges Project was investigated through the centrifuge model tests and numerical analyses and the strain and deformation of the cut-off wall were monitored [8-10]. Many numerical analyses have been carried out to investigate the interaction between overburden soils and the cut-off wall of embankment dams; so, the influence of the cut-off wall's thickness, the properties of alluvium deposits, the valley boundary, and the cut-off wall construction sequences on the stress-deformation behavior of cut-off walls have been studied [11, 12]. Also, Lee et al. [13], Al-Janabi et al. [14], Aboelela [15], Venkatesh and Karumanch [16], Jiang and He [17], Qiu et al. [18], and Kheiri et al. [19] in separate studies examined the seepage of various embankment dams around the world.

In this study, the numerical analysis of a mixed clay core embankment dam built on a deep overburden layer was conducted and the results were compared to those of actual instrumentations. In other words, the main purpose of this paper is to study the mechanical behavior, i.e., the settlements and the pore water pressure changes, of different zones of an embankment dam including its body, mixed clayey core, and plastic concrete cut-off wall. So, the Karkheh Large Embankment Dam constructed in the south-western part of Iran was considered as a case study and modelled using FLAC 2D during different phases including construction, impounding, and permanent seepage stages. The method implemented for the current study is the 2D-plane strain numerical modeling and analysis of an idealized critical cross section of the dam and foundation. First, a summary of the characteristics of the Karkheh Dam Project will be introduced. Then, principles of the modeling and analysis will be briefly described. Finally, the numerical analyses of the dam and foundation subjected to the simultaneous loadings of construction, water impounding, and steady state seepage phases will be introduced and the corresponding results will be presented. Moreover, the results corresponding to the settlements of the dam will be compared with those of obtained from a study performed using finite element method (FEM).

\section{The Karkheh Dam}

The Karkheh Dam constructed on the Karkheh River in the south-west of Iran is an embankment dam with a central clay core, a maximum height of $127 \mathrm{~m}$, and a crest length of $3030 \mathrm{~m}$. It was designed to irrigate 320,000 hectares of land, produce $520 \mathrm{MW}$ of hydro-electricity, and prevent downstream floods. The dam features a large volume of materials used in its construction (32 million cubic meters) and a big gross volume of the reservoir (7800 million cubic meters). Figure 1 presents the critical cross section of the dam and its foundation at station: $1+230 \mathrm{~km}$. It must be noted that more than 1000 instruments have been mounted within the Karkheh dam along 23 sections all over its length.

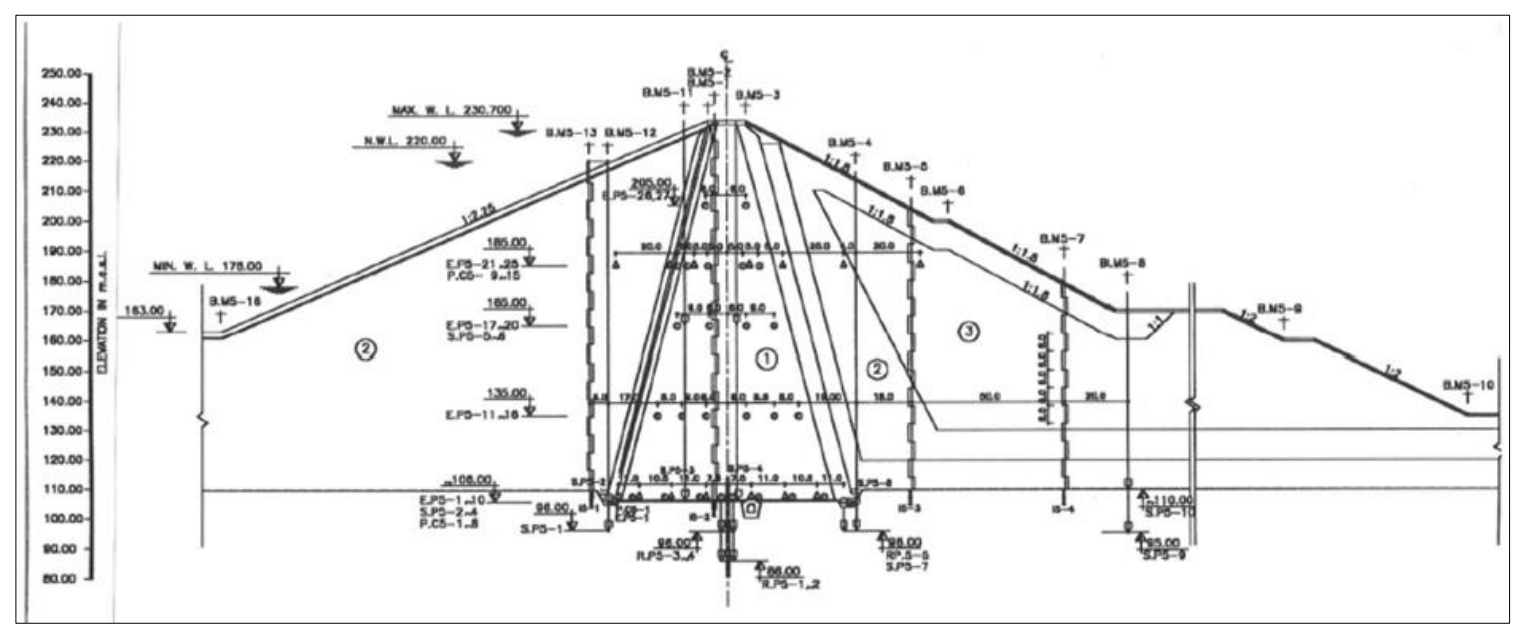

Figure 1 The critical cross section of the Karkheh Dam and its instrumentation arrangement 
The instrumentation arrangement in the foundation and body of the dam at the critical section of the dam, i.e., section 5-5 at St. $1+230.00 \mathrm{~km}$, is shown in Figure 1, as well [20, 21].

The dam's foundation comprises conglomerate material with mudstone layers. A plastic concrete cut-off wall was used for seepage control in the foundation of the Dam. The cut-off wall features a maximum depth in the foundation of about $80 \mathrm{~m}$ and a length of $2941 \mathrm{~m}$. The thickness of the wall varies from $0.6 \mathrm{~m}$ to $1 \mathrm{~m}$ in different sections according to the dam height. The top of the cut-off wall is embedded in the mixed clay core with embedment height varying from $2 \mathrm{~m}$ to $8 \mathrm{~m}$, depending on the dam height at the corresponding section. In the interface of the core and foundation, the cut-off wall is reinforced by constructing a trench filled with plastic concrete. More details about the Karkheh Dam Project were given by Soroush and Spandar [22].

\section{Material and methods}

\subsection{Finite Difference Model}

The Finite Difference Model was employed for the modeling and analysis of the dam and foundation cross section shown in Figure 2. So, a two dimensional, plane strain analysis of the Karkheh Dam was performed using 2D FLAC Software. The model requires elastic properties, a yield locus, a plastic potential function, and a flow rule which is non-associated to the shear-flow but associated to the tensile flow [23].

\subsection{Geometry and Materials}

The simplified finite difference mesh (FDM) used in the analyses of the entire dam body and the overburden foundation and the corresponding magnified mesh near the cut-off wall are shown in Figures 2 and 3. To simulate the embankment filling, each layer was modeled with thickness of $5 \mathrm{~m}$, totally 25 construction layers. Since the consolidation settlement of the overburden foundation has already been stable over thousands of years, the displacement of the overburden foundation was set to zero at the beginning of the calculation. However, the initial earth stress of the overburden foundation should be considered, which was calculated using the unbalanced force iterative method in the model. Moreover, the ground water level at the end of construction stage was assumed to be at the base of the dam.

In the analyses, to model the mechanical behavior of the materials, the Duncan-Chang model was used for the shell materials [24]. This model is the most typically and widely used; because, it can not only reflect the nonlinear characteristics of soils but also is suitable for a wide range of geotechnical materials. Moreover, in order to model the variations in the properties of the materials with the effective stress, i.e., internal friction angle and shear modulus, a number of functions were developed using software's built-in programming language, FISH, in addition to the built-in elasto-plastic model of Mohr-Coulomb. The provided FISH was used to introduce the hyperbolic nonlinear model in the static analyses as well. In the current study, the mechanical characteristics of the plastic concrete material used in the cut-off wall of the dam were considered based on the experimental investigations performed by Pashang Pisheh and Mir mohammad Hosseini $[25,26]$. So, the linear elastic modulus of the plastic concrete cut-off wall and the Poisson's ratio of this material were considered $400 \mathrm{MPa}$ and 0.22 , respectively [27]. The Young's modulus, E, and the bulk modulus, $\mathrm{B}_{\mathrm{t}}$, of the constitutive model are expressed as below:

\begin{tabular}{|c|c|}
\hline $\mathrm{E}=K p_{a}\left(\frac{\sigma_{3}}{p_{a}}\right)^{n}\left[1-\frac{R_{f}\left(\sigma_{1}-\sigma_{3}\right)(1-\sin \varphi)}{2 C \cos \varphi+2 \sigma_{3} \sin \varphi}\right]^{2}$ & $(1)$ \\
\hline $\mathrm{B}_{t}=K_{b} p_{a}\left(\frac{\sigma_{3}}{p_{a}}\right)^{m}$ & $(2)$ \\
\hline $\mathrm{E}_{u r}=K_{u r} p_{a}\left(\frac{\sigma_{3}}{p_{a}}\right)^{n}$ & (3) \\
\hline
\end{tabular}

Where, $\sigma_{1}$ and $\sigma_{3}$ are the major and minor principle stresses, respectively; $\mathrm{p}_{a}$ is the atmosphere pressure; $\mathrm{R}_{f}$ is the failure ratio; $K$ is the modulus number; $\mathrm{K}_{b}$ is the bulk modulus number; $n$ and $m$ are the exponents; $\mathrm{E}_{u r}$ and $\mathrm{K}_{u r}$ are the Young's modulus and modulus number under unloading and reloading conditions, respectively; $\varphi$ is the internal friction angle; and $C$ is the cohesive strength. 


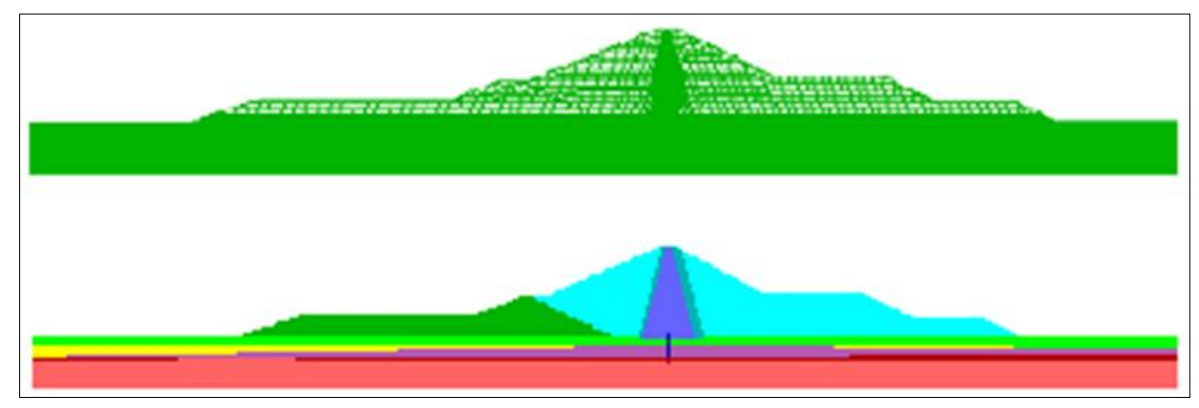

Figure 2 Finite difference grid generation and the dam general geometry

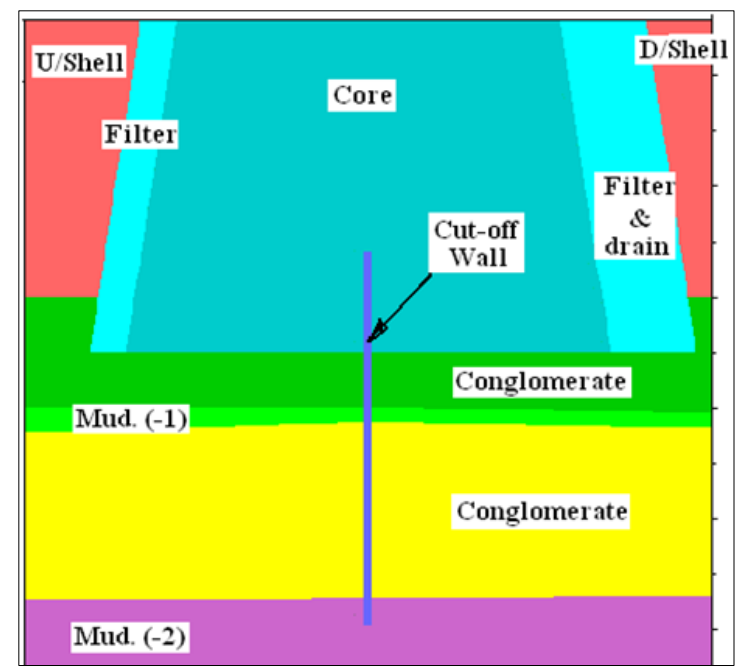

Figure 3 Magnified finite difference model at the core and cut-off wall of the dam

The parameters used for the analyses are shown in Table 1 , where $v$ is the poisons ration, $\mathrm{n}$ is porosity, $\mathrm{k}_{s}$ is the permeability coefficient, and $\rho$ is the density of the material.

Table 1 Material parameters used in the numerical analyses

\begin{tabular}{|l|c|l|l|l|l|l|l|l|l|l|}
\hline Material & $\boldsymbol{v}$ & $\mathbf{n}$ & $\boldsymbol{K}$ & $\boldsymbol{R}_{\boldsymbol{f}}$ & $\boldsymbol{K}_{\boldsymbol{u r}}$ & $\mathbf{C}(\mathbf{k p a})$ & $\boldsymbol{\varphi ( \mathbf { d e g } . )}$ & $\mathbf{E}(\mathbf{M p a})$ & $\mathbf{k}_{\boldsymbol{s}}(\boldsymbol{c m} / \boldsymbol{s})$ & $\boldsymbol{\rho}_{\text {sat }}\left(\frac{\boldsymbol{t o n}}{\boldsymbol{m}^{\mathbf{3}}}\right)$ \\
\hline Clay Core & 0.35 & 0.34 & 265 & 0.89 & 395 & 50 & 12 & 35 & $10^{-7}$ & 2.0 \\
\hline Rockfill Shell & 0.25 & 0.25 & 430 & 0.88 & 645 & 0 & 39 & 102 & $10^{-4}$ & 2.2 \\
\hline Filter \& Drains & 0.27 & 0.50 & 350 & 0.88 & 525 & 0 & 35 & 70 & $10^{-3}$ & 2.0 \\
\hline Plastic Concrete & 0.22 & 0.20 & --- & --- & --- & 800 & 28 & 400 & $10^{-7}$ & 2.2 \\
\hline Conglomerate & 0.25 & 0.45 & --- & --- & --- & 85 & 39 & 800 & $10^{-6}$ & 2.3 \\
\hline Mudstone & 0.30 & 0.35 & --- & --- & --- & 70 & 22 & 120 & $10^{-8}$ & 2.1 \\
\hline
\end{tabular}

\section{Results and discussion}

\subsection{End of Construction Stage}

Static analyses were carried out for various stages including end of construction, water impounding, and permanent seepage. The hyperbolic model proposed by Duncan and Chang [24] was used in these analyses. Generally, displacement of earth dams includes vertical and horizontal displacements. The vertical displacement is related to the weight and the 
consolidation of the dam materials. The horizontal displacement, on the other hand, mainly refers to the upstream movement of the dam due to the impounding of the reservoir which is associated with the rapid reduction of the effective stresses at the upstream of the dam as well as the downward movement of the dam due to the hydrostatic forces caused by the reservoir. The major settlement of the earth dams at the construction period is an immediate or elastic one. The rapid settlement is affected by the elastic behavior of the materials due to the successive loading of the new layers on the underlying layers and in a short time. To model the construction stage, the Karkheh Dam was modeled by dividing its total height into 25 layers the thickness of which were considered $5 \mathrm{~m}$. According to the layered construction of the dam and the resulted changes in the mechanical behavior of the embankment materials, the DuncanChang and Mohr-Coulomb models were implemented to simulate the layers and the displacements after each layer of filling. Figures 4 and 5 show the vertical and horizontal displacement contours of the dam at the end of the construction stage. As shown, the maximum settlement equal to $1.45 \mathrm{~m}$ occurs inside the clay core at the height of $65 \mathrm{~m}$; however, the horizontal displacement has symmetric contours with the maximum of $0.4 \mathrm{~m}$ at both up and downstream parts of the dam.

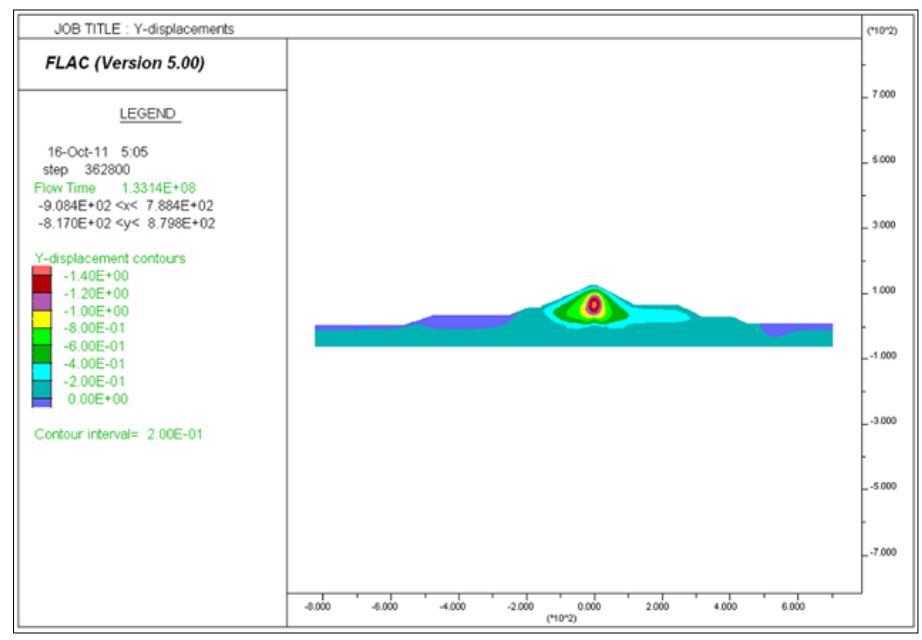

Figure 4 Vertical displacement contours at the end of the construction stage

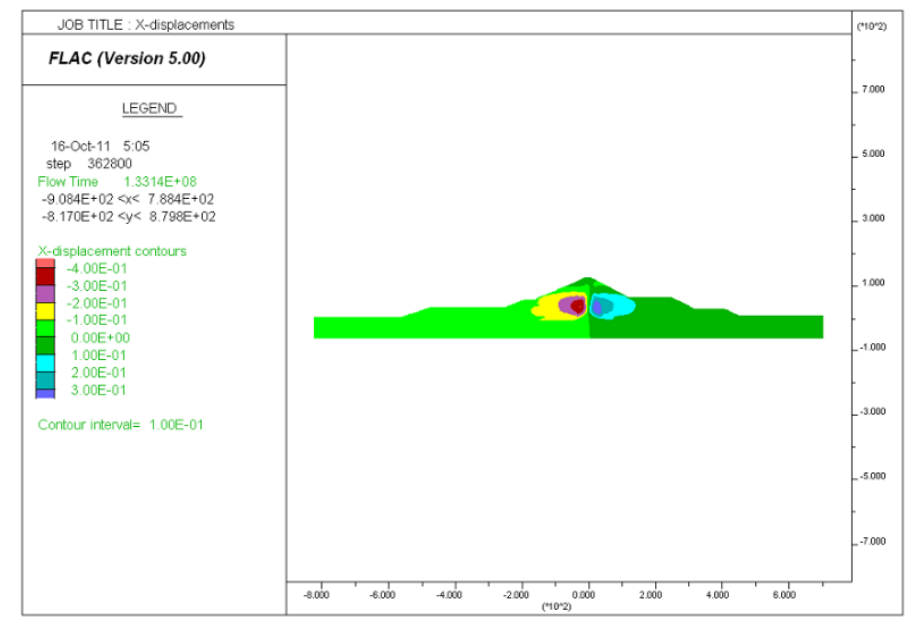

Figure 5 Horizontal displacement contours at the end of the construction stage

Figure 6 shows the results of the analyses for the vertical stress contours in various points of the Karkheh dam. As it can be seen, at the end of the construction stage, the vertical stress magnitudes in the clay core are clearly less than those in the adjacent points of the up and downstream shell, filter, and drains of the dam. This is because of the arching in the clay core which is resulted from the partial transfer of the weight of the more flexible, fine-grained core materials to the stiffer shell, filter, or abutment materials. This phenomenon leads to a reduction in vertical stresses in the core, 
increasing the risk of the hydraulic fracturing when the core is subjected to high water pressures during dam impoundment.

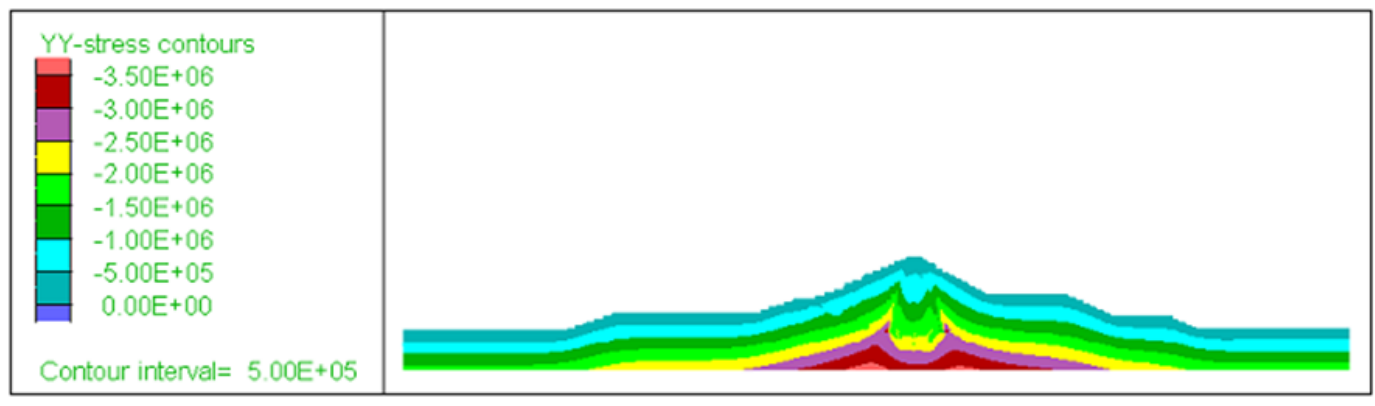

Figure 6 Vertical stress contours at the end of the construction stage

\subsection{Impounding and Permanent Seepage Stages}

Generally, the pore water pressure distribution within earth dams is caused by gravity seepage. The distribution of the pore pressure due to the gravity seepage is determined using the flow grid concept applied in the finite difference method. In the simulation of both the impounding of the reservoir and seepage of the dam, because of the very low permeability of the core in comparison with the shell and transition materials, the water pressure was directly applied on the upstream face of the mixed clay core as a mechanical hydrostatic pressure. A coupled flow and mechanical analysis has been done for modeling this stage. So, in the current study, the permanent seepage analyses of the Karkheh embankment dam were performed when the water level of the reservoir was at +220 MASL, i.e., 114 meters above the foundation level. Figures 7 and 8 illustrate the pore water pressure contours in the dam body and foundation in the permanent seepage stage. It is evident that the pore pressure changes occur very slowly in the upstream shell of the earth dam; however, in the regions near the clay core and cut-off wall due to the very low permeability parameters and the consequent sharp drop in the hydraulic head, the pore pressure changes happen more intense.

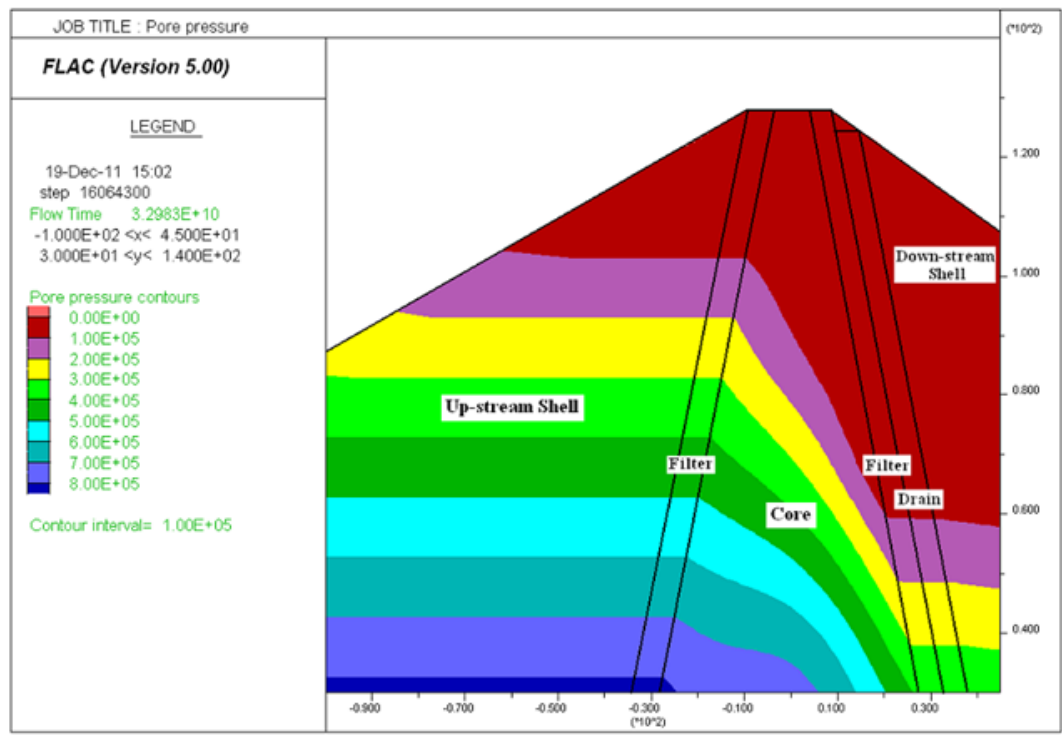

Figure 7 Pore pressure contours in the clay core at the permanent seepage stage

Considering the vertical stress for the total and effective states, it could be concluded that getting saturated the upstream part of the dam results in an increase in the total vertical stresses and decrease of the effective ones. Moreover, the results show that the impounding of the dam's reservoir results in increase in the horizontal displacements of the dam especially, in the vicinity of the clay core. At this stage, the maximum level of the horizontal deformations occurs in the downstream equal to $0.55 \mathrm{~m}$; however, these magnitudes reach $0.17 \mathrm{~m}$ at the crest of the dam.

Figure 9 shows the comparison between the current study's results for the horizontal displacement of the plastic concrete cut-off wall and those obtained from Soroush and Rayati [6] at the end of the construction and the steady state stages. It is clearly concluded that the maximum horizontal displacement of the cut-off wall has happened at the top of 
the wall in the clay core; this could be attributed to the lower deformability modulus of the clay core material rather than the stiffer conglomerate foundation.

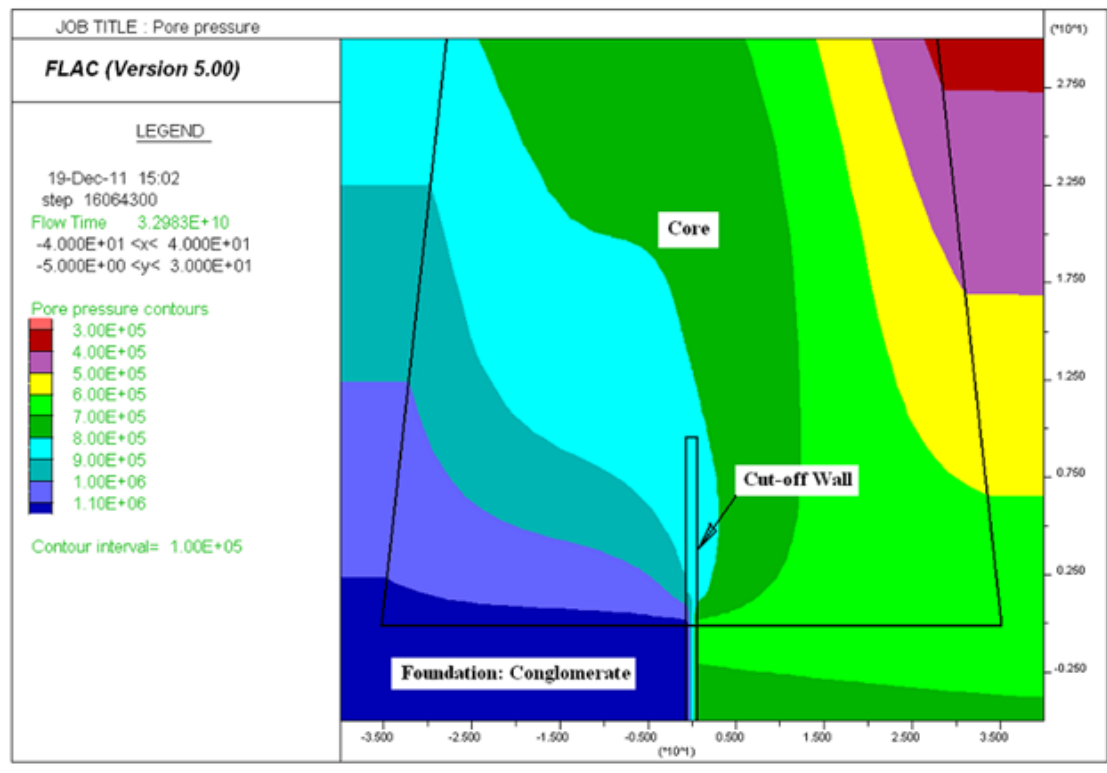

Figure 8 Pore pressure contours near the cut-off wall at the permanent seepage stage

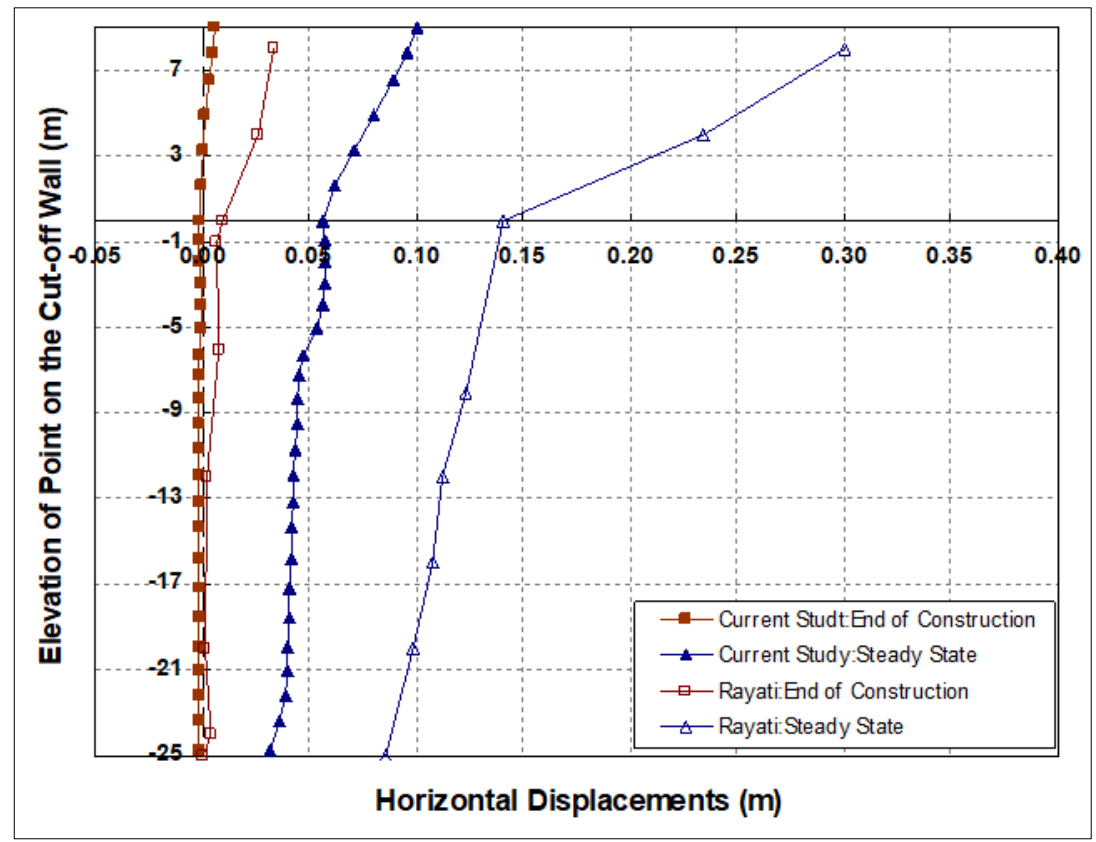

Figure 9 Comparison of the horizontal displacement of the plastic concrete cut-off wall

\subsection{Results of Instrumentation}

In this research, to verify the results of the analyses at the end of the construction stage, the results of the instrumentation for the parameters including the settlement and pore water pressure in the various heights of the clay core as well as the settlements of the up and downstream shell at the section $1+230 \mathrm{~km}$ of the dam were considered. Based on the results, the maximum settlement of the clay core at the end of the construction stage is measured equal to $1.26 \mathrm{~m}$ from the instrumentation data. This result is comparable to the corresponding value predicted in the numerical analyses of this stage equal to $1.45 \mathrm{~m}$. Figures 10 to 15 compare the instrumentation results for the pore water pressure and settlement changes during dam's construction with the corresponding results obtained from the numerical 
analyses. It is concluded that the instrumentation results are in a good agreement with those of the numerical simulation.

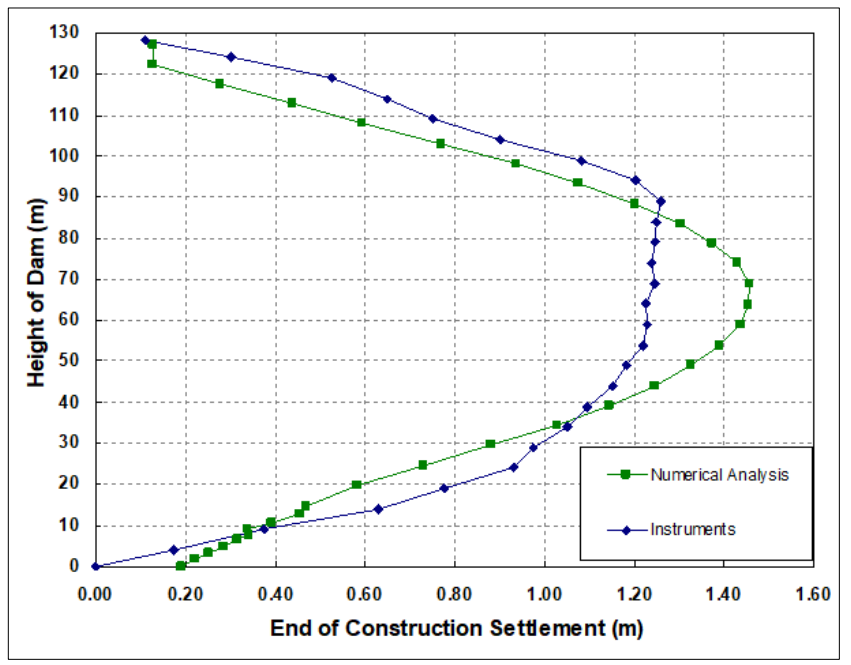

Figure 10 Comparison of the settlements obtained from the instrumentation and numerical analyses in different heights of the clay core

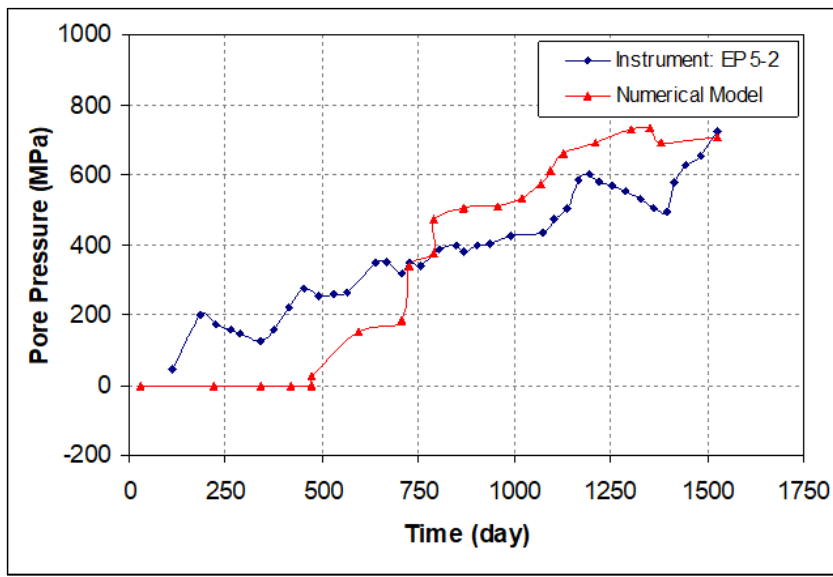

Figure 11 The pore pressure in the clay core obtained from the instrumentation and the numerical analyses (EP5-2, Height=106m)

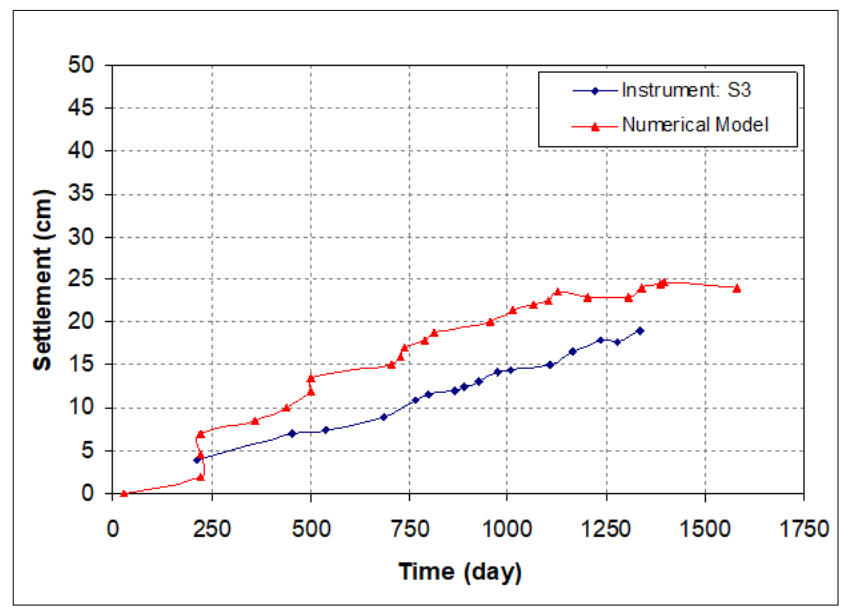

Figure 12 The settlement in the upstream shell obtained from the instrumentation and the numerical analyses (I5-1, Height $=120 \mathrm{~m}$ ) 


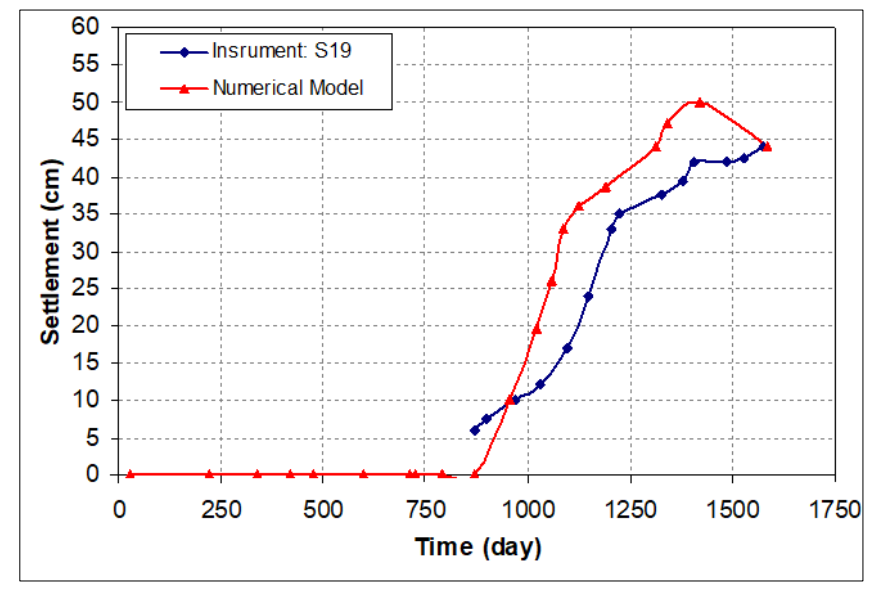

Figure 13 The settlement in the upstream shell obtained from the instrumentation and the numerical analyses (I5-1, Height $=180 \mathrm{~m}$ )

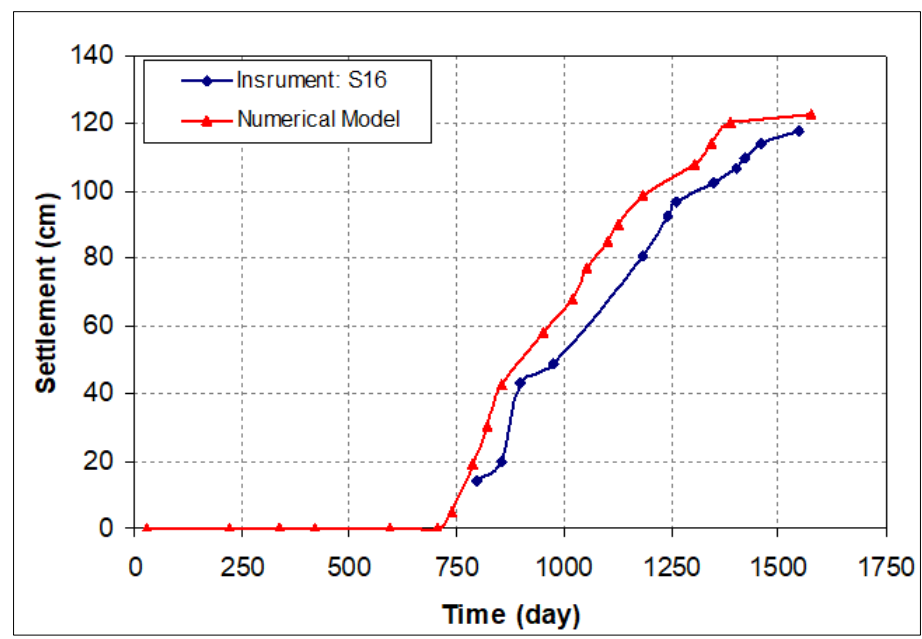

Figure 14 The settlement in the clay core obtained from the instrumentation and the numerical analyses (I5-2, Height $=165 \mathrm{~m}$ )

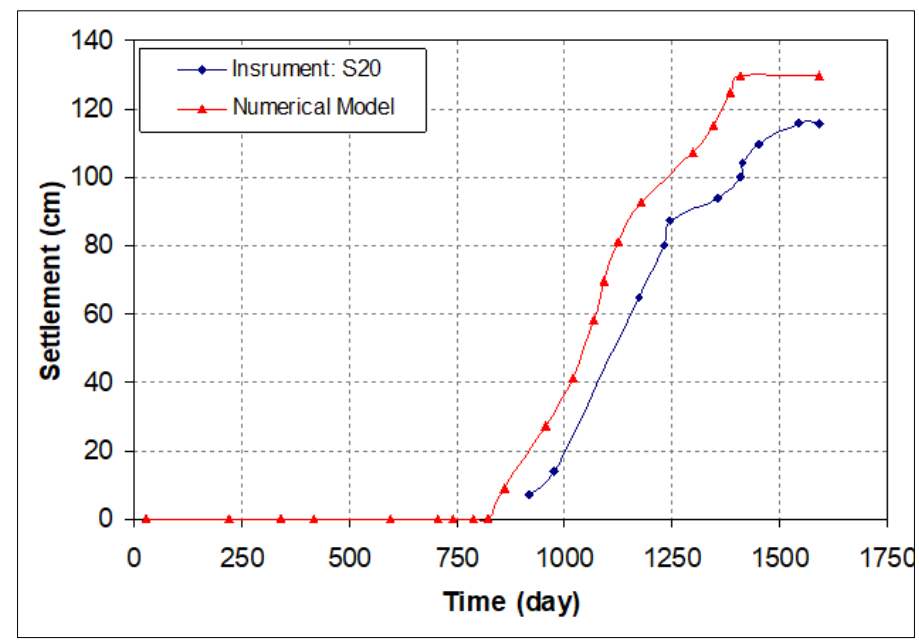

Figure 15 The settlement in the clay core obtained from the instrumentation and the numerical analyses (I5-2, Height $=180 \mathrm{~m}$ ) 


\section{Conclusion}

In this study, the numerical analyses of the Karkheh Embankment Dam and its foundation including the cut-off wall carried out using finite difference method (FDM). The results of the analyses confirm that the critical embankment slope at the end of the construction is the upstream slope. Based on the current study results, the following conclusions can be drawn:

- At the end of the construction stage, the maximum settlement equal to $1.45 \mathrm{~m}$ occurs inside the clay core of the dam at the height of $65 \mathrm{~m}$; however, the horizontal displacement has symmetric contours with the maximum of $0.4 \mathrm{~m}$ at both up and downstream parts of the dam.

- After impounding of the reservoir and steady state seepage stage, the maximum magnitude of the horizontal deformations occurs in the downstream of the dam equal to $0.55 \mathrm{~m}$; however, this magnitude reaches $0.17 \mathrm{~m}$ at the crest of the dam.

- The maximum horizontal deformations in the cut-off wall occur in the higher elevations of the wall where the cut-off wall is embedded in the clay core of the dam. This could be attributed to the lower deformability modulus of the mixed clay core material rather than the stiffer conglomerate foundation.

\section{Compliance with ethical standards}

\section{Acknowledgments}

The authors gratefully acknowledge the Civil and Environmental Engineering Department of Amirkabir University of Technology for supporting this work.

\section{Disclosure of conflict of interest}

The authors declare that no conflict of interest identified by the authors regarding what is exposed in this article.

\section{References}

[1] Feizi-Khankandi S, Mirghasemi AA, Ghalandarzadeh A, Hoeg K. Cyclic Triaxial Tests on Asphalt Concrete as a Water Barrier for Embankment Dams. Soils and Foundations. 2008; 48(3): 319-332.

[2] Pashang Pisheh Y, Mir Mohammad Hosseini SM, Ganjian N, Shakiba Nia K. Investigation of Critical Depth of Liquefaction in Soil Deposits Containing Double Loose Sand Lenses. GeoFlorida 2010: Advances in Analysis, Modeling \& Design. 2010; 3072-3079.

[3] Pashang Pisheh Y, Mir Mohammad Hosseini SM. Numerical simulation of cyclic behavior of double sand lenses and corresponding liquefaction-induced soil settlement. Journal of Central South University of Technology. 2010; 17(3): 593-602.

[4] Pashang Pisheh Y. Mechanism of Soil Deformation due to Double Lenses Liquefaction and Critical Depth Determination [M.Sc. Thesis]. Tehran, Iran: Civil and Environmental Engineering Department, Amirkabir University of Technology. 2004.

[5] Hinchberger S, Weck J, Newson T. Mechanical and hydraulic characterization of plastic concrete for seepage cutoff walls. Canadian Geotechnical Journal. 2010; 47(4): 461-471.

[6] Soroush A, Rayati M. NUMERICAL ANALYSIS OF KARKHEH DAM, FOUNDATION, AND ITS CUTOFF WALL SUBJECTED TO EARTHQUAKE LOADING. Proceedings of 13th World Conference on Earthquake Engineering, Vancouver, British Colombia, Canada. 2004; 2114.

[7] ICOLD (International Commission on Large Dams). Filling Materials for Watertight Cut-off Walls. 1985; Bulletin 51.

[8] Bao CG. Bao Chenggang Selected Papers on Study of Geotechnical Engineering. Changjiang Press, Wuhan. 2007.

[9] Zhang XP, Bao CG, Zhang JS. The displacement and operation of impervious cores in phase-cofferdam of Three Gorges Project. Journal of Hydraulic Engineering. 2000; 31(9): 91-96.

[10] Cheng ZL. Strain status of vertical impervious wall in TGP stage-2 upstream cofferdam. Journal of Yangtze River Scientific Research Institute. 2004; 21(6): 31-37. 
[11] Pan Y, He YL, Zhou XX, Cao XX. Analysis of effect of canyon terrain on stress and displacement of cutoff wall in dam foundation with deep overburden. Rock and Soil Mechanics. 2013; 34(7): 2023-2030.

[12] Ding YH, Zhang QG, Zhang BY. FEM analysis of stress-deformation characteristics of cut-off walls in high core rockfill dam. Journal of Hydroelectric Engineering. 2013; 32(3): 162-167.

[13] Lee JW, Kim J, Kang GC. Seepage behavior of earth dams considering rainfall effects. Advances in Civil Engineering. 2018:1-9.

[14] Al-Janabi AM, Ghazali AH, Ghazaw YM, Afan HA, Al-Ansari M, Yaseen ZM. Experimental and numerical analysis for earthfill dam seepage. Sustainability. 2020; 12(2490):1-12.

[15] Aboelela MM. Control of seepage through earth dams based on pervious foundation using toe drainage systems. Journal of Water Resource and Protection. 2016; 8: 1158-1174.

[16] Venkatesh K, Karumanch SR. Distribution of pore water pressure in an earthen dam considering unsaturatedsaturated seepage analysis. E3S Web Conf. 2016; 9(19004): 1-5.

[17] Jiang Z, He J. Detection model for seepage behavior of earth dams based on data mining. Mathematical Problems in Engineering. 2018; Article ID 8191802:11.

[18] Qiu J, Zheng D, Zhu K. Seepage monitoring models study of earth-rock dams influenced by rainstorms. Mathematical Problems in Engineering. 2016; Article ID 1656738:11.

[19] Kheiri G, Javdanian H, Shams G. A numerical modeling study on the seepage under embankment dams. Modeling Earth Systems and Environment. 2020; 6: 1075-1087.

[20] Soroush A. Plastic concrete cut-off wall in the Karkheh Dam: review of some construction aspects and a summary of the opinions of the expert panel. Proceedings of 52nd Canadian Geotechnical Conference. 1999; 575-582.

[21] Soroush A, Soroush M. Parameters affecting thickness of bentonite cake-a physical model study. Proceedings of 53rd Canadian Geotechnical Conference. 2000; 1005-1011.

[22] Soroush A, Spandar K. A laboratory study on plastic concrete under different confining pressures. Proceedings of 3rd Iranian international conference on geotechnical engineering \& soil mechanics. 2002; 3: 17-23.

[23] User's Manual, FLAC: Fast Lagrangian Analysis Continua. Itasca Consulting Group, Inc., Minneapolis, MN, USA.

[24] Duncan JM, Chang CY. Non-linear Analysis of Stress and Strain in Soils. Journal of the Soil Mechanics and Foundations, Div. 1970; SM5: 7513.

[25] Pashang Pisheh Y, Mir Mohammad Hosseini SM. Stress-strain behavior of plastic concrete using monotonic triaxial compression tests. Journal of Central South University of Technology. 2012; 19(4): 1125-1131.

[26] Pashang Pisheh Y, Mir Mohammad Hosseini SM. Experimental Investigation of Mechanical Behavior of plastic concrete in Cutoff Walls. ASCE, Journal of Materials in Civil Engineering. 2019; 31(1).

[27] Pashang Pisheh Y, Mir Mohammad Hosseini SM. Laboratory Study on the Cyclic and Post-cyclic Behavior of Plastic Concrete Used in Cut-off Walls of Embankment Dams. ASCE, Journal of Materials in Civil Engineering. 2020; 32(5). 